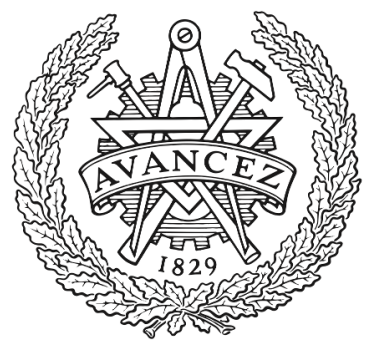

CHALMERS

UNIVERSITY OF TECHNOLOGY

\title{
Design of an Asymmetrical Quadruple-ridge Flared Horn Feed: a Solution to Eliminate Polarization Discrepancy in the Offset Reflecting Systems
}

Downloaded from: https://research.chalmers.se, 2023-04-26 10:32 UTC

Citation for the original published paper (version of record):

Dong, B., Yang, J., Pantaleev, M. et al (2018). Design of an Asymmetrical Quadruple-ridge Flared Horn Feed: a Solution to Eliminate Polarization Discrepancy in the Offset Reflecting Systems. IET Conference Publications, 2018(CP741)

N.B. When citing this work, cite the original published paper. 


\section{Design of an Asymmetrical/Elliptical Band-B Feed:}

a Solution to Eliminate Polarization Discrepancy in the Offest SKA dish

Bin Dong ${ }^{1}, \underline{\text { Jian Yang }}{ }^{2}$, Miroslav Pantaleev ${ }^{3}$, Jonas Flygare ${ }^{3}$ Bhushan Billade ${ }^{3}$

${ }^{1}$ National Astronomical Observatories, Chinese Academy of Sciences (CAS), Beijing, China

${ }^{2}$ Dept. of Electrical Engineering, Chalmers University of Technology, Goteborg, Sweden

${ }^{3}$ Onsala Space Observatory, Dept. of Space, Earth and Environment, Chalmers University of Technology, Goteborg,

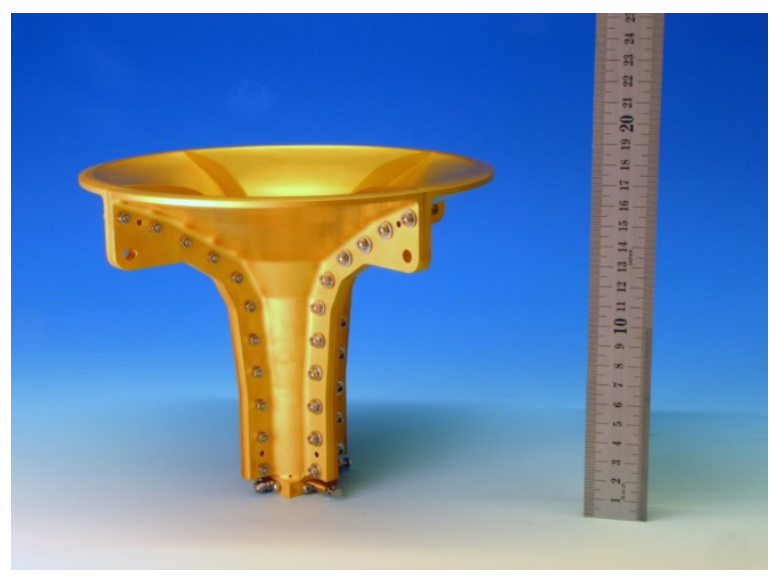
Sweden 